\title{
Experimental and Quantum Chemical Studies of the Inhibition of Copper with Sodium Dodecyl Sulphate (SDS) in Acidic Medium
}

\author{
Mojisola O. Nkiko" ${ }^{1,2}$, Abayomi Oluwabi2 ${ }^{2}$ Sikiru A. Ahmed ${ }^{3}$, Janet T. Bamgbose ${ }^{2}$ \\ ${ }^{1}$ Department of Physical and Chemical Sciences, Elizade University, Ilara-Mokin, Nigeria \\ ${ }^{2}$ Department of Chemistry, Federal University of Agriculture, Abeokuta, Nigeria \\ ${ }^{3}$ Department of Chemical Sciences, Kwara State University Malete, Ilorin, Nigeria \\ Email: ${ }^{*}$ chrismoj3@yahoo.co.uk
}

How to cite this paper: Nkiko, M.O., Oluwabi, A., Ahmed, S.A. and Bamgbose, J.T. (2018) Experimental and Quantum Chemical Studies of the Inhibition of Copper with Sodium Dodecyl Sulphate (SDS) in Acidic Medium. Engineering, 10, 851-862. https://doi.org/10.4236/eng.2018.1012059

Received: March 30, 2018

Accepted: December 25, 2018

Published: December 28, 2018

Copyright $\odot 2018$ by authors and Scientific Research Publishing Inc. This work is licensed under the Creative Commons Attribution International License (CC BY 4.0).

http://creativecommons.org/licenses/by/4.0/

\begin{abstract}
This work investigates the inhibitive properties of sodium dodecyl sulphate (SDS) on the corrosion of copper $(\mathrm{Cu})$ in nitric acid using gasometric methods. The inhibition efficiency increases with time and concentration of SDS. The corrosion rate of copper decreases as concentration of SDS increases. Adsorption of the SDS on the surface obeyed the Langmuir adsorption isotherm. The high negative values of the kinetic parameter B suggest that the inhibitor's effectiveness increases with temperature. The equilibrium constant and the free energy of adsorption of SDS to copper are negative and large. This observation implies that the adsorption mechanism maybe chemisorption. The quantum chemical calculation of copper dodecyl sulphate shows that the energy change in the HOMO-LUMO energy of the moiety is positive and small. This observation implies that the SDS is an efficient inhibitor. The high dipole moment obtained implies that corrosion inhibition of $\mathrm{Cu}$ is enhanced by adsorption of SDS and this observation correlates with the observed experimental inhibition efficiency.
\end{abstract}

\section{Keywords}

Corrosion Inhibition, Copper, Gasometric Methods, Adsorption, Inhibition Efficiency, Sodium Dodecyl Sulphate (SDS)

\section{Introduction}

Copper exhibits excellent electrical, thermal and mechanical properties that makes it a relatively noble metal used for various applications in building construction, machinery, equipment and consumer products to mention a few [1] 
[2] [3].

Corrosion is an age long problem affecting infrastructures, production, and transportation in the industrial sector. Various organic compounds and natural inhibitors are proven methods of preventing and controlling corrosion of metals. The choice of corrosion inhibitors depend on cost, toxicity, availability and biodegradability of the substance because of the environment [4]-[13]. It has also been reported that inhibitors reduce corrosion rate through modification of corrosion potential, retardation of cathodic and anodic corrosion reactions via polarization and passivation of the metal surface, and by adsorption to the metal surface [14] [15] [16]. Copper is corrosion resistant in water but corrodes easily in acid and alkaline solutions. Various researches have shown that the passivation layer built in copper is from simple $\mathrm{Cu}_{2} \mathrm{O}$ or a duplex of $\mathrm{Cu}_{2} \mathrm{O} / \mathrm{CuO} \cdot \mathrm{Cu}(\mathrm{OH})_{2}$ structure and it depends on the $\mathrm{pH}$ of solution and the electrode potential [14] [15].

Hayon et al. [1] have studied corrosion of Copper in borate solutions and observed using electrochemical DC at $\mathrm{pH} 7.5$ that there is no passivity breakdown of copper in the presence of SDS. They have also shown that dodecyl sulphate ions accelerate anodic dissolution of copper metal to $\mathrm{Cu}^{2+}$, at low $\mathrm{pH}$. They attributed the breakdown in passivity in the presence of SDS to the formation of $\mathrm{Cu}(\mathrm{DS})_{2}$ complex. Studies have shown that SDS acts as inhibitor for corrosion of metals like nickel, aluminium, steel, in chloride medium and mild steel, stainless steel and also copper in acidic medium [16] [17]. Sodium dodecyl sulphate is a surfactant whose presence even at very low concentrations in any medium provides desirable properties useful to many processes in petrochemical, food, paint, detergent and coating industries. The adsorption of surfactants on metal surfaces is extremely important in corrosion inhibition and metallic electro deposition. The surface of the surfactants on electrodes have been shown to have significant effects on the kinetics of electron transfer at electrodes including surface blocking, and electrostatic interactions between solutes and adsorbed surfactants. Mobin et al. and Igua et al. suggested that the interaction between surfactants and the metal surface is related to the structure of the absorbed species [17] [18]. It has been reported that corrosion inhibition of surfactants is related to its ability to aggregate at interfaces and in solution and corrosion inhibition by surfactant depends on its concentration [19] [20].

The current trend of correlating experimental and quantum chemical studies of inhibitors and the successful application of density functional theory have kindled much interest in studying the inhibitor efficiency of sodium dodecyl sulphate (SDS) on copper in acidic medium. Quantum chemical studies have been deployed to relate the molecular properties of different organic compounds their inhibition efficiencies [21]-[27]. The molecular and electronic parameters obtained from these calculations include the energy gap obtained from the highest occupied molecular orbital (HOMO) and the lowest occupied molecular orbital LUMO. The difference in the energy for the HOMO-LUMO transition is an 
indicator of the efficiency of the inhibitor been studied [22] [23] [24] [25].

This study investigates the molecular properties using the density functional theory (DFT) of the inhibitor efficiency of sodium dodecyl sulphate (SDS) an anionic surfactant on the corrosion of copper in nitric acid solution. The hardness and the tensile strength of copper metal in the with and without sodium dodecyl sulphate are analyzed.

\section{Materials and Methods}

Copper (99.9\%) and Sodium dodecyl sulphate (SDS) molecular formula $\mathrm{C}_{12} \mathrm{H}_{25} \mathrm{NaO}_{4} \mathrm{~S}$ was purchased from Fessy electrical company Ibadan, Nigeria and Surechem Ltd. England respectively. Nitric acid $\left(\mathrm{HNO}_{3}\right)$ was obtained from Aldrich Chemical and Co. The copper sheet was mechanically pressed cut into different coupons of dimension $2 \mathrm{~cm}$ by $2 \mathrm{~cm}$ by $0.3 \mathrm{~cm}$. Each coupon was polished and drilled at one end, degreased in acetone, dried and preserved in air tight desiccator at room temperature. The stock solution of $1 \mathrm{M}$ SDS was prepared in 10 $\mathrm{mL} \mathrm{HNO}_{3}$ from which working concentrations of $2.75 \mathrm{mM}, 3.5 \mathrm{mM}, 7.0 \mathrm{mM}$ and $10 \mathrm{mM}$ were prepared by simple dilution. Corrosion studies were carried out using gasometric method. This method involves measuring the volume of gas evolved when a metal reacts with an acid from the cathodic reaction of the corrosion process and this is proportional to the rate of corrosion [28]. $100 \mathrm{~mL}$ of the corrodent $\left(2 \mathrm{M} \mathrm{HNO}_{3}\right)$ was poured into the two necked flask, the initial volume of air in the graduated burette was noted, and the Copper coupon of approximately $4 \mathrm{~g}$ was immersed into the corrodent, the flask was quickly closed and the volume of $\mathrm{H}_{2}$ gas evolved from reaction was monitored by volume change in the graduated burette at different time intervals of about 3 hours. Measurements were carried out in duplicate.

The corrosion of copper in $2 \mathrm{M} \mathrm{HNO}_{3}$ was characterized by rapid evolution of $\mathrm{H}_{2}$ gas. The rate was also calculated with and without sodium dodecyl sulphate (SDS) using the Equation (1)

$$
C_{R H}=\frac{V_{t}-V_{i}}{t_{t}-t_{i}}
$$

where $V_{t}$ and $V_{i}$ are volumes of $\mathrm{H}_{2}$ evolved at time $t_{t}$ and $t_{i}$ respectively, $C_{R H}$ is the corrosion rate. The inhibition efficiency was also calculated using:

The rate of evolution of gas $(R V)$ is obtained from the slope of the graph plotted for volume of gas evolved against time.

$$
\begin{gathered}
R V=\frac{\Delta V}{\Delta T} \\
\% I=\frac{R V_{\text {blank }}-R V_{\text {inh }}}{R V_{\text {blank }}}
\end{gathered}
$$

Inhibitor surface area of coverage $\theta$ is calculated from the expression

$$
\theta=\frac{\% I}{100}
$$


where $R V_{\text {blank }}$ and $R V_{\text {inh }}$ are the rate of evolution of gas with and without SDS respectively, $\% I$ is the percentage inhibition efficiency.

\section{Computational Studies}

Quantum chemical calculations using density functional theory (DFT) were simulated using "SPARTAN" $10 \mathrm{nI}$ software [29]. The calculated parameters include the highest occupied molecular orbital (HOMO), the lowest occupied molecular orbital (LUMO), dipole moment $(\mu)$, ionization potential $(I)$, electron affinity $(A)$, absolute electronegativity $(\chi)$, absolute hardness $(\eta)$, global softness $(\sigma)$ and electrophilicity index $(\omega)$ were obtained from the optimized molecular structure.

Using the Koopmans theorem, [30];

Ionization potential " $P$ " $=-E_{\mathrm{HO} о}$;

Electron affinity " $A$ " $=-E_{\mathrm{LUMO}}$.

The absolute hardness $\eta$ and global softness $\sigma$ were calculated [31] as follows,

Absolute hardness " $\eta$ " $=\frac{E_{\text {HOMO }}-E_{\text {LUMO }}}{2}$.

Global softness “ $\sigma$ " $=\frac{1}{\eta}$.

Electrophilicity index “ $\omega$ " $=\frac{\chi}{2 \eta}$.

\section{Result and Discussion}

\subsection{Gasometric Measurement}

The corrosion of copper in $2 \mathrm{M} \mathrm{HNO}_{3}$ in the with and without Sodium dodecyl sulphate has been studied at $30^{\circ} \mathrm{C}$ using gasometric methods. Table 1 shows the inhibition efficiency and the rate of evolution of gas at different concentrations of SDS.

The Inhibition efficiency (I.E) increases as the concentration of Sodium dodecyl sulphate (SDS) increases with a maximum I.E of $52.03 \%$ at $0.30 \mathrm{~g} / \mathrm{L}$ of SDS. The rate of evolution of gas deceases as SDS concentration and inhibition efficiency increases. This implies that more SDS molecules were adsorbed on the

Table 1. Percentage inhibition efficiency of sodium dodecyl sulphate at different concentrations at $30^{\circ} \mathrm{C}$.

\begin{tabular}{cccc}
\hline $\begin{array}{c}\text { SDS } \\
\begin{array}{c}\text { concentration } \\
(\mathrm{g} / \mathrm{L})\end{array}\end{array}$ & $\begin{array}{c}\text { Rate of evolution of } \\
\text { gas }(\mathrm{RV})\end{array}$ & $\begin{array}{c}\text { Surface coverage of } \\
\text { adsorption }(\theta)\end{array}$ & $\begin{array}{c}\text { Inhibition efficiency } \\
(\%)\end{array}$ \\
\hline 0.05 & 0.186 & 0.3137 & 31.37 \\
0.10 & 0.183 & 0.3247 & 32.47 \\
0.15 & 0.179 & 0.3395 & 33.95 \\
0.20 & 0.153 & 0.4354 & 43.54 \\
0.25 & 0.145 & 0.4649 & 46.95 \\
0.30 & 0.130 & 0.5203 & 52.03 \\
\hline
\end{tabular}


surface of copper forming a protective layer that inhibits its corrosion (Table 1, Figure 1).

\subsection{Kinetic and Thermodynamic Treatment of Gas Evolution Result}

Assuming that the plot of corrosion rate $(C R)$ of copper in the presence of SDS against concentration of inhibitor-SDS (Figure 2) obeys the kinetic relationship in Equation (5)

$$
\log C R=\log k+B \log C
$$

And B obtained from the slope in Figure 2 is defined as the reaction constant which measures the effectiveness of the inhibitor while $\mathrm{k}$ is the rate constant of the reaction. [4] [32] [33] [34] [35]

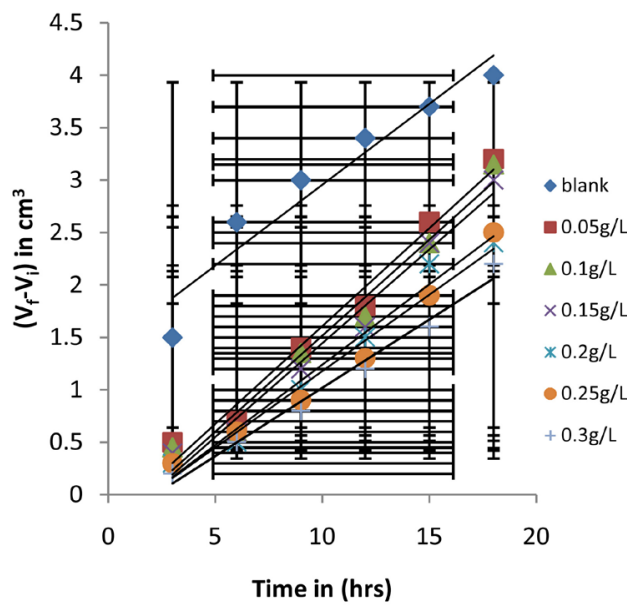

Figure 1. Volume of gas evolved versus time of copper in $2 \mathrm{M} \mathrm{HNO}_{3}$ with and without of SDS at $30^{\circ} \mathrm{C}$.

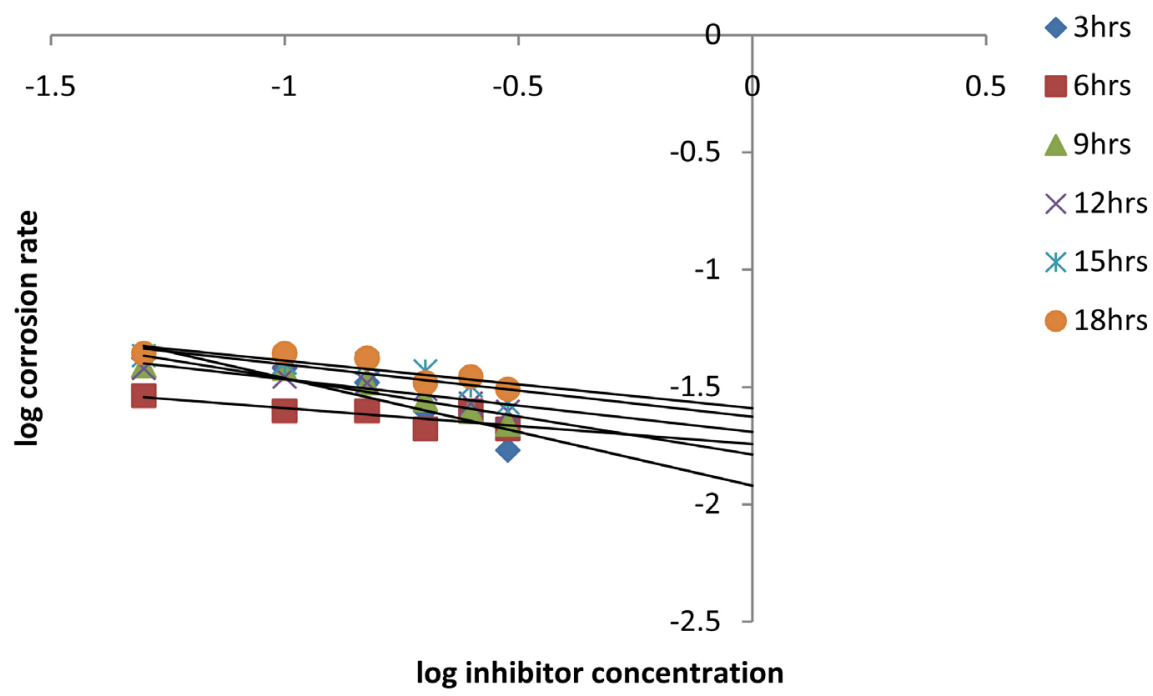

Figure 2. Variation of log corrosion rate log concentration of SDS for corrosion of copper in $2 \mathrm{M} \mathrm{HNO}_{3}$ at $30^{\circ} \mathrm{C}$. 
The values of B obtained for this experiment are negative (Table 2). This implies that the rate of corrosion is inversely proportional to the concentrations of SDS. SDS becomes more effective as its concentration increases. The negative value of B decreases in magnitude as the time increases which implies that SDS effectiveness will increase with temperature.

The rate constant $k$, defined as the corrosion rate at the inhibitor concentration of unity increases with time as expected of a first order kinetics. The adsorption isotherm fitted the Langmuir model (Figure 3) and the equilibrium constant for adsorption $K_{a d s}$ obtained from Equation (6).

$$
\frac{C_{i n h}}{\theta}=\frac{1}{K_{a d s}}+C_{i n h}
$$

where $C_{i n h}$ is the concentration of inhibitor and $\theta$ is the degree of surface coverage.

The free energy of adsorption $\Delta G_{a d s}$ obtained from Equation (7). The enthalpy

Table 2. Kinetic parameters for corrosion inhibition of copper in the presence of SDS at $30^{\circ} \mathrm{C}$.

\begin{tabular}{cccc}
\hline Time of immersion (hours) & $B$ & $\log k$ & $k \times 10^{-2}\left(\mathrm{hr}^{-1}\right)$ \\
\hline 3 & -0.4580 & -1.9198 & 1.2028 \\
6 & -0.1524 & -1.7423 & 1.8101 \\
9 & -0.3244 & -1.7881 & 1.6289 \\
12 & -0.2244 & -1.6912 & 2.0361 \\
15 & -0.2231 & -1.6269 & 2.3610 \\
18 & -0.2024 & -1.5896 & 2.5728 \\
\hline
\end{tabular}

Table 3. Thermodynamic parameters for inhibition of corrosion of copper in the presence of SDS at $30^{\circ} \mathrm{C}$.

\begin{tabular}{cccc}
\hline$K_{a d s}$ & $\Delta G_{a d s} \mathrm{~kJ} / \mathrm{mol}$ & $\Delta H_{a d s} \mathrm{~kJ} / \mathrm{mol}$ & $\Delta S_{\text {ads }} \mathrm{J} / \mathrm{mol} / \mathrm{K}$ \\
\hline 7.4349 & -75.0556 & -5.0538 & 231.0290 \\
\hline
\end{tabular}

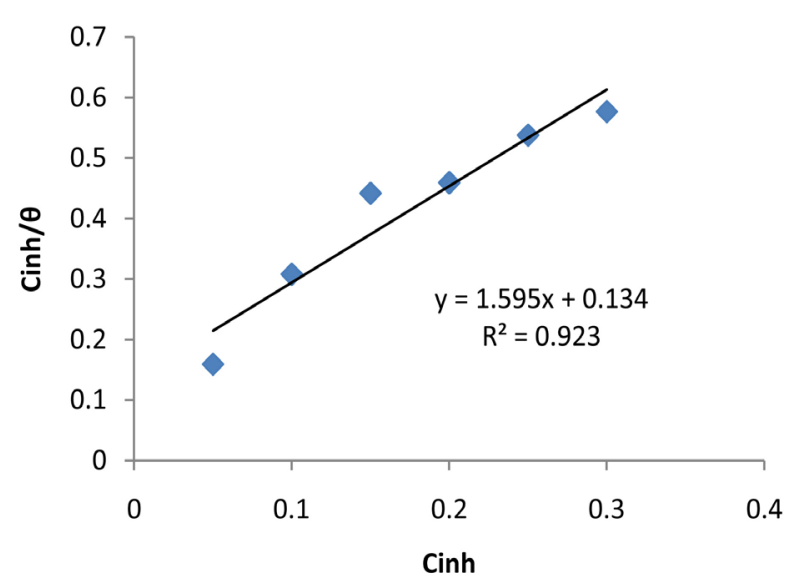

Figure 3. Langmuir adsorption isotherm for the corrosion inhibition of copper with SDS at $30^{\circ} \mathrm{C}$. 
$\Delta H_{a d s}$ for the process obtained from van't Hoff Equation (8) and the entropy $\Delta S_{a d s}$ from the Gibbs Equation (9) is shown in Table 3.

$$
\begin{gathered}
\ln K_{a d s}=\ln \left(55^{-1}\right)-\Delta G_{a d s}\left(R T^{-1}\right) \\
\ln K_{a d s}=\frac{-\Delta H_{a d s}}{R T}+C \\
\Delta G_{a d s}=\Delta H_{a d s}+T \Delta S_{a d s}
\end{gathered}
$$

The value of $K_{\text {ads }}$ for this experiment is positive and small and $G_{\text {ads }}$ is negative and large $(\sim-75.06 \mathrm{~kJ} / \mathrm{mol})$. The negative value of $\Delta G_{a d s}$ shows that the reaction is spontaneous. The negative large value of $\Delta G_{a d s}$ obtained in his experiment is consistent with charge transfer or sharing from the sodium dodecyl sulphate (SDS) to the metal surface to form a coordinate bond between the metal and inhibitor which implies the mechanism of adsorption is chemisorption. Generally negative values of the magnitude $-40 \mathrm{~kJ} / \mathrm{mol}$ or more signify chemisorptions [7] [12]. The negative value of $\Delta H_{a d s}$ implies that adsorption process is exothermic.The entropy of adsorption $\Delta S_{\text {ads }}$ is $231.0290 \mathrm{~J} / \mathrm{mol} / \mathrm{K}$ is positive. This observation indicates that the adsorption of SDS on copper shows an ordered system.

\subsection{Quantum Chemical Treatment of Data}

Quantum chemical calculations using density function theory (DFT were simulated using Spartan 10 software. The properties calculated were obtained after geometric optimization of the structures as shown in Figures 4(a)-(c). and the calculated quantum chemical parameters obtained in this study tabulated as 4 .

"The frontier orbital molecular theory of chemical reactivity shows that transition of electron is due to interaction between highest occupied molecular orbital $(H O M O)$ and the lowest unoccupied molecular orbital (LUMO) of reacting species" [24] [36].

The quantum mechanical parameter which represents the ionization potential and the ability of a molecule to donate electron to an acceptor with an empty molecular orbital of lower energy is $E_{\mathrm{HOMо}}$ [37]. The inhibitor SDS $E_{\mathrm{HOMо}}$ obtained is $-9.97 \mathrm{eV}$ and that of copper dodecyl sulphate (CDS) is $-9.43 \mathrm{eV}$ implies that SDS donates electrons to the unoccupied $\mathrm{d}$ orbital of $\mathrm{CU}^{2+}$ ion and also accepts electrons from the metal ion to form a feedback bond (Figure 4(c)).

The ease of forming a feedback bond depends on the value of $E_{\mathrm{LUMO}}$. The lower the $E_{\mathrm{LUmo}}$ the easier it is for the inhibitor to accept electrons from the $d$ orbital of the metal [38] [39]. The $E_{\mathrm{LUMO}}$ observed for this experiment is -1.27 $\mathrm{eV}$ which implies that the inhibitor SDS will accept electrons from the $\mathrm{d}$ orbital of copper metal.

The band gap energy $\Delta E$ is a function of adsorption of inhibitor on the surface of a metal, a decrease in $\Delta E$ implies an increase in reactivity and inhibition efficiency of the molecule. The calculated $\Delta E$ value for this study is $8.7 \mathrm{eV}$ which implies the highest inhibition efficiency and reactivity are in agreement with experimental observations. 


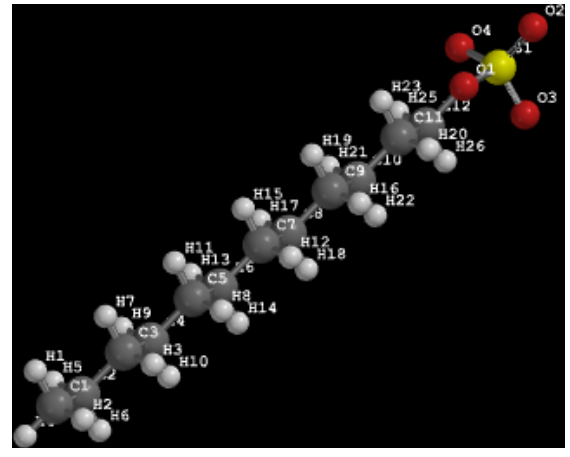

(a)

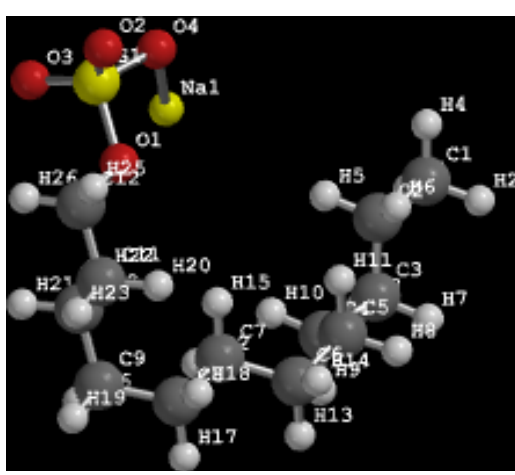

(b)

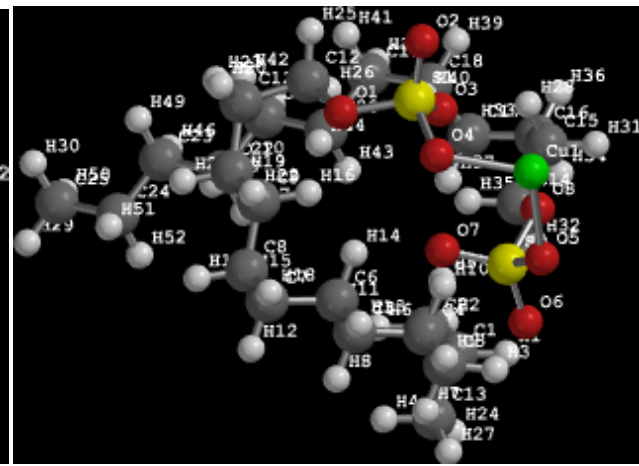

(c)

Figure 4. (a) Optimized structure of Dodecylsulphate (DS); (b) Optimized geometry of Sodium Dodecylsulphate (SDS); and (c) Optimized geometry of Copper Dodecyl sulphate (CDS).

Table 4. Computational data of corrosion of copper in the presence of sodium dodecyl sulphate obtained using SPARTAN $10 \mathrm{nI}$.

\begin{tabular}{cccc}
\hline Parameters & $\begin{array}{c}\text { Dodecyl } \\
\text { sulphate } \\
(\mathrm{DS})\end{array}$ & $\begin{array}{c}\text { Sodium } \\
\text { Dodecyl } \\
\text { sulphate (SDS) }\end{array}$ & $\begin{array}{c}\text { Copper } \\
\text { Dodecyl } \\
\text { sulphate (CDS) }\end{array}$ \\
\hline$E_{\mathrm{LUMO}}(\mathrm{eV})$ & $-0.58 \mathrm{eV}$ & $-1.27 \mathrm{eV}$ & $-1.31 \mathrm{eV}$ \\
$E_{\mathrm{HOMO}}(\mathrm{eV})$ & $-11.13 \mathrm{eV}$ & $-9.97 \mathrm{eV}$ & $-9.43 \mathrm{eV}$ \\
$\Delta E=E_{\mathrm{LUMO}}-E_{\mathrm{HOMO}}(\mathrm{eV})$ & $10.55 \mathrm{eV}$ & $8.7 \mathrm{eV}$ & $8.12 \mathrm{eV}$ \\
Dipole moment, $\mu($ Debye $)$ & $2.48 \mathrm{Debye}$ & $11.19 \mathrm{Debye}$ & $3.52 \mathrm{Debye}$ \\
Ionization energy, $I(\mathrm{eV})$ & $11.13 \mathrm{eV}$ & $9.97 \mathrm{eV}$ & $9.43 \mathrm{eV}$ \\
Electron affinity, $A(\mathrm{eV})$ & $0.58 \mathrm{eV}$ & $1.27 \mathrm{eV}$ & $1.31 \mathrm{eV}$ \\
Absolute electronegativity, $\chi(\mathrm{eV})$ & $5.86 \mathrm{eV}$ & $5.62 \mathrm{eV}$ & $5.37 \mathrm{eV}$ \\
Absolute hardness, $\eta(\mathrm{eV})$ & $5.28 \mathrm{eV}$ & $4.35 \mathrm{eV}$ & $4.06 \mathrm{eV}$ \\
Global softness, $\left.\sigma(\mathrm{eV})^{-1}\right)$ & $0.189 \mathrm{eV}^{-1}$ & $0.230 \mathrm{eV}$ & $0.246 \mathrm{eV}$ \\
Electrophilicity index, $\omega(\mathrm{eV})$ & $3.252 \mathrm{eV}^{-1}$ & $3.630 \mathrm{eV}$ & $3.551 \mathrm{eV}$ \\
Total energy change, $\Delta E_{T}(\mathrm{eV})$ & $-1.32 \mathrm{eV}$ & $-1.09 \mathrm{eV}$ & $1.02 \mathrm{eV}$ \\
\hline
\end{tabular}

The stability and the reactivity of the molecule are measured by its hardness or softness. Absolute hardness and global softness are measure of the molecular stability and reactivity of a molecule. A hard molecule has a large $\Delta E$ while a soft 
molecule has small $\Delta E$ value [40]. Soft molecules donate electrons with ease and efficiently so they are more reactive than hard molecules [3]. The data obtained in this study for SDS (Table 4) indicates a low value for absolute hardness at $4.35 \mathrm{eV}$ and high value for global softness at $0.23 \mathrm{eV}$; this implies that SDS is a soft molecule and an efficient electron donor and inhibitor. This observation is in agreement with Abdel Raham et al. [3].

The dipole moment $\mu$ describes the polarity of a molecule [41]. The high dipole moment observed at 11.9D for SDS will probably increase its absorption to the metal surface as earlier proposed by Kikuchi [42]. The total energy calculated by the quantum chemical method for this study is $-1.09 \mathrm{eV}$ is the minimum total energy which in agreement with Ju and Li [43] "is the total energy of the system in the presence of static external potential and it is a function of the charge density. The electronic charge density which gave rise to this minimum energy is the exact single particle ground state energy".

\section{Conclusions}

- Inhibition efficiency of SDS increases as the concentration of SDS increases and the rate of evolution of gas decreases as SDS concentration decreases.

- The effectiveness SDS as an inhibitor of corrosion of copper will likely increase with temperature as indicated by the value of $B$ the reaction constant.

- The free energy of the reaction is large and negative which suggests that SDS is chemically adsorbed i.e. mechanism of adsorption is chemisorptions.

- Quantum chemical parameters for Cu-SDS shows a good correlation between the electronic structure of SDS and its potential as an inhibitor for the corrosion of copper.

\section{Conflicts of Interest}

The authors declare no conflicts of interest regarding the publication of this paper.

\section{References}

[1] Hayon, J., Yarnitzky, C., Yahalom, J. and Bettelheim, A. (2002) Surface Processes, Characterization for the Corrosion of Copper in Borate Solutions: I. The Effect of Sodium Dodecyl Sulfate. Journal of the Electrochemical Society, 149, B314-B320. https://doi.org/10.1149/1.1480016

[2] Singh, A.K. and Qurashi, M.A. (2010) Piroxican: A Novel Corrosion Inhibitor for Mild Steel Corrosion in $\mathrm{HCl}$ Solution. Journal of Materials and Environmental Science, 1, 101-110.

[3] Abdel Rahman, H.H., Moustafa, A.H.E. and Awad, M.K. (2012) Potentiodynamic and Quantum Studies of Some Amino Acids as Corrosion Inhibitors for Copper. International Journal of Electrochemical Science, 7, 1266-1287.

[4] Nkiko, M.O. and Bamgbose, J.T. (2011) Corrosion Inhibitive Effect of Ocimum Gratissimum Extract on Zinc-Aluminum Alloy in Hydrochloric Acid. Portugaliae Electrochimica Acta, 29, 419-427. https://doi.org/10.4152/pea.201106419

[5] Omotosho, O.A., Ajayi, O.O., Fayomi, O. and Yusuff, O.O. (2012) Degradation 
Evaluation of Zinc in 2M Hydrochloric Acid in the Presence of Bambosa Bamboo. Singapore Journal of Scientific Research, 1-11.

[6] Nkiko, M.O., Oguntoyinbo, E.S., Bamgbose, J.T. and Bamgbade, A.A. (2014) Protection of Zinc Alloy in $\mathrm{H}_{3} \mathrm{PO}_{4}$ Using Extract of Lantana Camara. Life Science Journal, 1111, 809-904.

[7] Niamien, P.M., Kouassi, H.A., Trokourrey, A., Essy, F.K., Sissouma, D. and Bokra, Y. (2012) Copper Corrosion Inhibition in $1 \mathrm{M} \mathrm{HNO}_{3}$ by Two Benzimidazole Derivatives. ISRN Material Science, 1-15.

[8] Akalezi, C.O. and Oguzie, E.E. (2015) Evaluation of Anticorrosion Properties of Chrysophyllum Albidum Leaves Extract for Mild Steel Protection in Acidic Medium. International Journal of Industrial Chemistry, 1-12.

[9] Ebenso, E.E., Ebenso, U.J., Eddy, N.O. and Odongenyi, A.O. (2009) Inhibition of the Corrosion of Mild Steel by Methocarbamol. Portugaliae Electrochimica Acta, 27, 13-22. https://doi.org/10.4152/pea.200901013

[10] Ravari, F.B. (2009) Investigation on Two Salent Type Schiff Base Compounds as Corrosion Inhibition of Copper in $0.5 \mathrm{MH}_{2} \mathrm{SO}_{4}$. Journal of Science, 22, 175-182.

[11] Noor, E.A. (2008) Comparative Study of Corrosion Inhibition of Mild Steel by Aqueous Extract of Fenugreek Seeds and Leaves in Acidic Solution. Journal of Engineering and Applied Sciences, 3, 23-30.

[12] Obot, I.B., Obi-Egbedi, N.O., Umoren, S.A. and Ebenso, E.E. (2010) Synergistic and Antangonistic Effects of Anions and Ipomea Invulcrata as green Corrosion Inhibito for Aluminium Dissolution in Acidic Medium. International Journal of Electrochemical Science, 5, 994-1007.

[13] Sanjay, K.S., Acknez, M., Gargi, J. and Jyoti, S. Corrosion Inhibition and Adsorption Properties of Azadirachta Indica Mature Leaves Extract as Green Inhibitor for Mild Steel in $\mathrm{HNO}_{3}$. Green Chemistry Letters and Reviews, 3, 7-15.

[14] Maurice, V., Strehblow, H.H. and Marcus, P. (1998) Passivity and Its Breakdown. In: Natishan, P.M., Isaacs, H.S., Junik-Czachor, V., Macagao, A., Marcus, P. and Seo, M., Eds., The Electrochemical Society Proceeding Series, Penington, 907.

[15] Collisi, U. and Strehblow, H.H. (1990) The Formation of $\mathrm{Cu}_{2} \mathrm{O}$ Layers on $\mathrm{Cu}$ and Their Electrochemical and Photoelectrochemical Properties. Journal of Electroanalytical Chemistry and Interfacial Electrochemistry, 284, 385-401. https://doi.org/10.1016/0022-0728(90)85046-8

[16] Villami, R.F.V., Curio, P., Agostinho, S.M.L. and Rubim, J.C. (1999) Effect of Sodium Dodecyl Sulfate on Copper Corrosion in Sulphuric Acid Media in the Presence and Absence of Benzotriazole. Journal of Electroanalytical Chemistry, 472, 112-119. https://doi.org/10.1016/S0022-0728(99)00267-3

[17] Mobin, M., Parveen, M. and Rafiquee, M.Z.A. (2017) Synergistic Effect of Sodium Dodecyl Sulfate and Cetyltrimethyl Ammonium Bromide on the Corrosion Inhibition Behavior of 1-Methionine on Mild Steel in Acidic Medium. Arabian Journal of Chemistry, 10, S1364-S1372.

[18] Muñoz, A.I., Antoni, J.G., Guiñón, J.L. and Herranz, V.P. (2004) Comparison of Inorganic Inhibitors of Copper, Nickel and Copper-Nickels in Aqueous Lithium Bromide Solution. Electrochimica Acta, 50, 957-966. https://doi.org/10.1016/j.electacta.2004.07.048

[19] Saleh, M.M. and Atia, A.A. (2006) Effect of Structure of the Ionic Head of Cationic Surfactant on Its Inhibition of Acid Corrosion of Mild Steel. Journal of Applied Electrochemistry, 36, 899-905. https://doi.org/10.1007/s10800-006-9147-6 
[20] Migahed, M.A. and Al-Sabagh, A.M. (2009) Beneficial Role of Surfactants as Corrosion Inhibitors in Petroleum Industry: A Review Article. Chemical Engineering Communications, 196, 1054-1075. https://doi.org/10.1080/00986440902897095

[21] Liu, P., Fang, X., Tang, Y.M., Sun, C.N. and Yao, C. (2011) Electrochemical and Quantum Chemical Studies of 5-Substituted Tetrazoles as Corrosion Inhibitors for Copper in Aerated $0.5 \mathrm{M} \mathrm{H}_{2} \mathrm{SO}_{4}$ Solution. Materials Sciences and Applic, 2, 1268-1278. https://doi.org/10.4236/msa.2011.29171

[22] Obayes, H.R., Alwan, G.H., Alobady, A.H.M., Al-Amiery, A.A., Kadhum, A.A.H. and Mohammad, A.B. (2014) Quantum Chemical Assessment of Benzimidazole Derivatives as Corrosion Inhibitors. Chemistry Central Journal, 8, 21. https://doi.org/10.1186/1752-153X-8-21

[23] Al Hamzi, A.A., Zarrok, H., Zarrouk, A., Salghi, R., Hammouti, B., Al-Deyab, S.S., Bouachrine, M., Amine, A. and Guenoun, F. (2013) The Role of Acridin-9(10H)One in the Inhibition of Carbon Steel Corrosion: Thermodynamic, Electrochemical and DFT Studies. International Journal of Electrochemical Science, 8, 2586-2605.

[24] Gece, G. (2008) The Use of Quantum Chemical Methods in Corrosion Inhibitor Studies. Corrosion Science, 50, 2981-2992.

https://doi.org/10.1016/j.corsci.2008.08.043

[25] Khalil, N. (2003) Quantum Chemical Approach of Corrosion Inhibition. Electrochimica Acta, 48, 2635-2640. https://doi.org/10.1016/S0013-4686(03)00307-4

[26] Xia, S.W., Oiu, M., Yu, L.M., Liu, F.G. and Zhao, H.Z. (2008) Molecular Dynamics and Density Functional Theory Study on Relationship between Structure of Imidazoline Derivatives and Inhibition Performance. Corrosion Science, 50, 2021-2029. https://doi.org/10.1016/j.corsci.2008.04.021

[27] Li, X.H., Deng, S.D. and Fu, H. (2011) Synergistic Effect of 6-Benzylaminopurine and Iodide Ion on the Corrosion of Cold Rolled Steel in $\mathrm{H}_{3} \mathrm{PO}_{4}$ Solution. Corrosion Science, 53, 3704-3711. https://doi.org/10.1016/j.corsci.2011.07.016

[28] Onuchukwu, A.I. and Adamu, A.A.I. (1990) The Kinetics and Mechanism of Hydrogen Evolution on Corroding Aluminum in Alkaline Medium. Materials Chemistry and Physics, 25, 227-235. https://doi.org/10.1016/0254-0584(90)90067-K

[29] SPARTAN'10, Build 1.01 Wavefunction Inc., Irvine, CA (2011).

[30] Parr, R.G. and Pearson, R.G. (1983) Absolute Hardness: Companion Parameter to Absolute Electronegativity. Journal of the American Chemical Society, 105, 75127516. https://doi.org/10.1021/ja00364a005

[31] Pearson, R.G. (1988) Absolute Electronegativity and Hardness: Application to Inorganic Chemistry. Inorganic Chemistry, 27, 734-740. https://doi.org/10.1021/ic00277a030

[32] Noor, E.A. (2007) Temperature Effects on the Corrosion Inhibition of Mild Steel in Acidic Solutions by Aqueous Fengreek Leaves. International Journal of Electrochemical Science, 2, 996-1017.

[33] Atkins, P.W. and De Paula, J. (2006) Physical Chemistry. Oxford Press, New York.

[34] Thomas, J.M. and Thomas, W.J. (1981) Introduction to the Principles of Heterogeneous Catalysis. 5th Edition, Academic Press, London.

[35] Atkins, P.W. (1980) Chemisorbed and Physiosorbed Species: A Text Book of Physical Chemistry. Oxford Press, New York, 936-938.

[36] Domenicano, A. and Hasgittae, I. (1992) Accurate Molecular Structure: Their Determination and Importance. Oxford University Press, New York.

[37] Dewar, M.J.S. and Thiel, W. (1977) Ground States of Molecules. 38. MNDO Me- 
thod. Approximations and Parameters. Journal of the American Chemical Society, 99, 4899-4907. https://doi.org/10.1021/ja00457a004

[38] Musa, A.Y., Kadhum, A.H., Mohamad, A.B., Rahoma, A.A.B. and Mesmari, H. (2010) Electrochemical and Quantum Chemical Calculations on 4,4-Dimethyloxazolidine-2-thione as Inhibitor for Mild Steel Corrosion in Hydrochloric Acid. Journal of Molecular Structure, 969, 233-237. https://doi.org/10.1016/j.molstruc.2010.02.051

[39] Amin, M.A., Khaled, K.F. and Fadl-Allah, S.A. (2010) Testing Validity of the Tafel Extrapolation Method for Monitoring Corrosion of Cold Rolled Steel in HCl Solutions-Experimental and Theoretical Studies. Corrosion Science, 52, 140-151. https://doi.org/10.1016/j.corsci.2009.08.055

[40] Gece, G. and Bilgiç, S. (2009) Quantum Chemical Study of Some Cyclic Nitrogen Compounds as Corrosion Inhibitors of Steel in $\mathrm{NaCl}$ Media. Corrosion Science, 51, 1876-1878. https://doi.org/10.1016/j.corsci.2009.04.003

[41] Ebenso, E.E., Isabirye, D.A. and Eddy, N.O. (2010) Adsorption and Quantum Chemical Studies on the Inhibition Potentials of Some Thiosemicarbazides for the Corrosion of Mild Steel in Acidic Medium. International Journal of Molecular Sciences, 11, 2473-2498. https://doi.org/10.3390/ijms11062473

[42] Kikuchi, O. (1987) Systematic QSAR Procedures with Quantum Chemical Descriptions. Quantitative Structure-Activity Relationships, 6, 179-184. https://doi.org/10.1002/qsar.19870060406

[43] Ju, H., Kai, Z.-P. and Li, Y. (2008) Aminic Nitrogen-Bearing Polydentate Schiff Base Compounds as Corrosion Inhibitors for Iron in Acidic Media: A Quantum Chemical Calculation. Corrosion Science, 50, 865-871. https://doi.org/10.1016/j.corsci.2007.10.009 